\title{
Effect of Cohesive Property of Carbon Black on Electrical Conduction of CB-Resin Composites
}

\author{
Shuhei Nakamura, Atsushi Ito, Goro Sawa, Kazunari Tsubota,* \\ Masayuki IKedA, ${ }^{*}$ and Teiji KuBO* \\ Department of Electronics, Mie University, Tsu 514, Japan \\ *NEC Corporation, Sagamihara 229, Japan
}

(Received October 2, 1989)

\begin{abstract}
The temperature dependence of carbon black(CB)-resin composites has been studied in the wide temperature range from $-160^{\circ} \mathrm{C}$ to $220^{\circ} \mathrm{C}$ by changing the curing temperature. Resistance of the composite decreases at first and increases around $70^{\circ} \mathrm{C}$ and then irreversibly decreases above the glass transition temperature of binder resin for ascending temperature. The minimum and maximum of resistance on the temperature dependence have been discussed from the point of view of cohesive property of CB particle and physical property of resin.

KEY WORDS Carbon Black / Epoxy / Electrical Property / Compsoite /

Resistor /
\end{abstract}

Many experimental efforts on carbon black(CB)-resin composites have been devoted over several decades to electrical studies of the basic phenomena. They have discussed the physical basis and mathematical formalism for the three important processes such as percolation, tunneling and thermal expansion which are controlling the electrical conduction.

Percolation theory predicts a sharp increase in the conductivity at a critical volume fraction of conductor, which is approximately 0.25 for a random dispersion of irregularly shaped particles. ${ }^{1-3}$ However, the critical volume fraction for $\mathrm{CB}$-resin composite strongly depends on the natures of binder resin and $\mathrm{CB}$ particle. For example, the higher polarity of a polymer gives a larger critical volume fraction because a large surface tension of polymer produces a large excess energy in the polymer-CB interface. ${ }^{4} \mathrm{~A}$ highly structured carbon shows a small percolation threshold; even if the volume fraction of CB is less than 0.1 , a sharp increase of conductivity has been observed. ${ }^{5,6}$ Thus, CB-polymer composites are extremely complex in their percolative behavior in contrast to metal-particle-filled systems.

Change of the electrical conduction with temperature are dominated by the intrinsic matrix conduction and tunneling conduction across the thin layers separating neighboring CB particles. A quantum mechanical tunneling conduction has been presented by Sheng ${ }^{7}$ which is well applied to explain the temperature dependence of electrical conduction in CBpoly(vinyl chloride) composites at cryogenic temperatures below $100 \mathrm{~K}$.

Generally, the electrical conduction of CB-resin composites shows a U shaped dependence on temperature. ${ }^{8,9}$ The negative temperature coefficient (NTC) of resistance is ascribed to the tunneling conduction which is enhanced by thermally fluctuations. ${ }^{7,10,11}$ Amorphous carbon films also show NTC of resistivity above liq. $\mathrm{N}_{2}$ temperatures, which is explained by the thermally assisted hopping conduction mechanism. ${ }^{12}$ A large positive temperature coefficient (PTC) of resistance is observed near the melting point of polymer, being due to widening the gap between $\mathrm{CB}$ particles or decreasing of $\mathrm{CB}$ content by 
thermal expanison of resin. ${ }^{8,13-16}$ By heating the composite above melting point, the resistivity shows a mild decrease or sometimes a mild increase with acending temperature. ${ }^{15,16}$ The change of resistivity above melting points has not been discussed in detail. However, the sudden transition from PTC to NTC strongly depends on particle size, aggregate shape or structure, and porosity of CB. ${ }^{15,16}$

It is well known that the CB-resin resistor has an advantage due to its cheap manufacturing cost. However, there are also disadvantages such as a large temperature coefficient of resistance (TCR) and a large humidity coefficient of resistance (HCR). ${ }^{17}$ In order to improve the TCR and HCR of CB-polymer resistor, we have studied, at first, the mechanism of the electrical conduction of the composite by changing the properties of polymer and $\mathrm{CB} .{ }^{9}$ By incorporating the effect of thermal expansion of resin into the CB gap, the temperature dependence of resistance of CB-polymer composites from liq. $\mathrm{N}_{2}$ temperature to $150^{\circ} \mathrm{C}$ has been tried to explain using the thermally activated tunneling process. ${ }^{7}$ The modified tunneling process showed a change from NTC to PTC of resistance. However, the calculated results using the model could not explain the temperature dependence of the resistance on the CB content. ${ }^{9}$ Therefore, we have presented a model, which is based on a deliberately modified conduction mechanism based upon Scarisbric's model ${ }^{18}$ by incorporating thermal expanison of resin and thermally activated electrical conduction process. The conducting paths formed by CB particles was assumed to be a thermally activated process in the electrical conduction. And, the thermal expansion of resin was assumed to cause the conducting paths to break off or the gaps between CB particles to enlarge. This effect of thermal expansion of resin on the electrical conduction has been experimentally confirmed by changing the thermal expansion of resin. ${ }^{19}$ As a result of these competitive processes, the temperature dependence of the resistance shows a $U$ shaped curve for temperature. The model can explain a U-shaped dependence of resistance using reasonable parameters such as the activation energy of resistance in low temperatures, the thermal expansion coefficient of polymer, and the value of volume fraction of CB.

The cohesive property of $\mathrm{CB}$ particles is practically very important because the change of resistance by humidity is caused by enlarging the gaps due to swelling of the binder resin. This is the same mechanism to the temperature dependence of resistance, where the thermal expansion of resin is effective. ${ }^{19,20}$ Therefore, it is important how the cohesive property of CB can be changed by curing temperature.

In this paper, we shall exmaine the model from the point of view of a cohesive property of CB and a physical property of resin. The temperature, where the minimum of resistance appears, comes from a result of a competitive process between the NTC and PTC processes. Therefore, the temperature is a measure of the cohesive property of CB particles. It is one of the aim of this paper to clarify how the temperature giving the minimum resistance is changed by properties of $\mathrm{CB}$ or epoxy resin and by curing temperature.

The other aim of this paper is to describe the behavior of electrical conduction of the composite around the glass transition temperature of epoxy resin.

\section{EXPERIMENTAL}

In the experiments, six furnace CB's from low structure to high structure are used, and the physical and chemical properties of them are shown in Table I. They are listed from left side to right side in the order of from large surface area to small surface area. The CB1 is Black Pearls 2000 (Cabot Co., Ltd.), CB2 Ketjenblack EC (Japan EC Co., Ltd.), CB3 Vulcan XC-72 (Cabot Co., Ltd.), CB4 and CB5 MA600 and MA100, respectively, (Mitsubishi Petrochem. Co., Ltd.), and CB6 HS-500 (Asahi 
Table I. Physical and chemical properties of used carbon blacks

\begin{tabular}{lcccccc}
\hline & CB1 & CB2 & CB3 & CB4 & CB5 & CB6 \\
\hline $\begin{array}{c}\text { Surface are/ } \\
\mathrm{m}^{2} \mathrm{~g}^{-1}\end{array}$ & 1475 & 950 & 257 & 153 & 134 & 37 \\
$\begin{array}{c}\text { Oil absorption/ } \\
\text { /ml/100g } \\
\text { Particle size/ } \\
\mathrm{nm}\end{array}$ & 330 & 350 & 265 & 124 & 101 & 447 \\
\hline
\end{tabular}

Table II. Chemical properties of epoxy resins and blending ratio

\begin{tabular}{cccc}
\hline & WPE (g/eq) & Hardener & Accelerator \\
\hline E825 & 175 & $85 \mathrm{phr}$ & $1 \mathrm{phr}$ \\
E828 & 186 & $80 \mathrm{phr}$ & $1 \mathrm{phr}$ \\
\hline
\end{tabular}

Carbon Co., Ltd.) The physical and chemical properties of CB vary with particle size, porosity, and the oxygenated structures combined with their surface. Usually, a high structure CB, which has a large value of surface area or a large value of oil absorption, easily makes a good aggregation form for electrical conduction. ${ }^{21}$ The resins used were two kinds of glycidyl ether epoxy (E828 and E825, Yuka Shell Epoxy Co., Ltd.). The hardener used was acid anhydride (DX126, Yuka Shell Epoxy Co., Ltd.). The accelerator used was imidazole derivative (EMI24, Yuka Shell Epoxy Co., Ltd.). The blending ratio of them and chemical properties of resins are listed in Table II. The volume fraction of $\mathrm{CB}, f_{\mathrm{v}}$, which is the volume ratio of $\mathrm{CB}$ to the sum of volumes of $\mathrm{CB}$ and resin, and the experimental conditions such as curing temperature, $T_{\mathrm{c}}$, curing period are shown in each figure.

After mixing epoxy resin with $\mathrm{CB}$ for $1 \mathrm{~h}$ in vacuo, it was printed on a ceramic substrate using the screen method. The pattern is shown in Figure 1. After the pattern had been pre-cured for $2 \mathrm{~h}$ at $100^{\circ} \mathrm{C}$, it was cured mainly for $20 \mathrm{~h}$ at $165^{\circ} \mathrm{C}$ or $220^{\circ} \mathrm{C}$ in air.

Temperature dependence of the CB-resin composite was measured by heating at

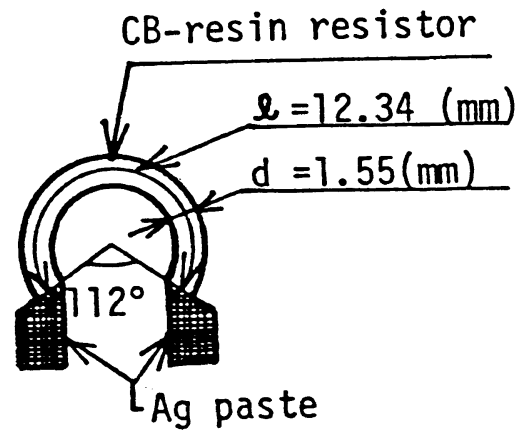

Figure 1. Printed pattern of the CB-resin composite by the screen method.

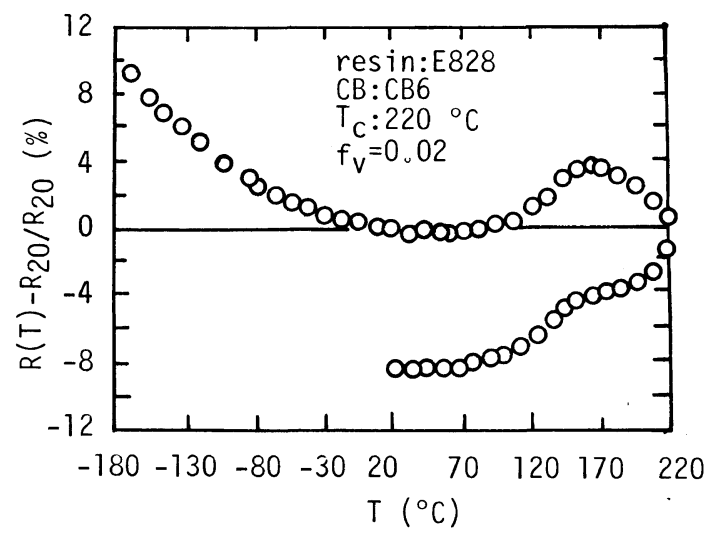

Figure 2. Typical temperature dependence of the resistance of CB-resin composite. (Resistivity, $\rho$, of each resistor is about $10^{2} \Omega \mathrm{cm}$.)

$1^{\circ} \mathrm{C} \mathrm{min}^{-1}$ from about $-160^{\circ} \mathrm{C}$ to $220^{\circ} \mathrm{C}$ in vacuo. The change of resistance is expressed as a percent change of resistance for the resistance, $R_{20}$, at $20^{\circ} \mathrm{C}$; the resistance, $R_{20}$, is used as a reference.

\section{RESULTS}

Figure 2 shows a typical temperature dependence of the CB-resin composite. It can be seen from $-160^{\circ} \mathrm{C}$ to $220^{\circ} \mathrm{C}$ that the resistance once decreases and then starts to increase around $70^{\circ} \mathrm{C}$ and finally decreases again for ascending temperature. At $220^{\circ} \mathrm{C}$, the temperature was held for $10 \mathrm{~min}$. After that, the composite was cooled down without 


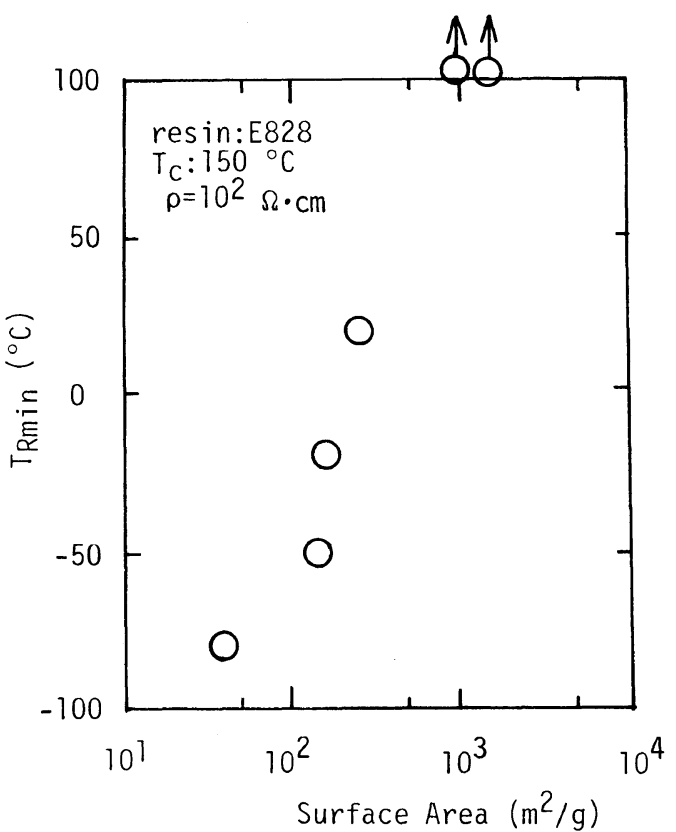

Figure 3. $T_{R \min }$ as a function of surface area, $S A$, of CB. (Each volume fraction of the composite varies from sample to sample, but the resistivities for them are constant at $10^{2} \Omega \mathrm{cm}$.)

electrical power. Then, the resistance was irreversibly decreased. When heating was below about $140^{\circ} \mathrm{C}$, the temperature dependence of the resistance traced the same path for heating and cooling cycles. As there are a minimum of resistance around $45^{\circ} \mathrm{C}$ and a maximum around $165^{\circ} \mathrm{C}$ on heating cycle, we shall discuss the temperatures $T_{\mathrm{R}_{\text {min }}}$ and $T_{\mathrm{R} \max }$, at which the resistance shows a minimum and maximum, respectively.

\section{Experimental Results in Low Temperature}

From the point of view of the property of $\mathrm{CB}$, the $T_{\mathrm{R} \text { min }}$ strongly depends on the surface area, SA, of CB as shown in Figure 3, where each resistivity for the composites made of various CB's is almost about $10^{2} \Omega \mathrm{cm}$. Because the $T_{R \text { min }}$ 's for $C B 1$ and $C B 2$ are beyond $100^{\circ} \mathrm{C}$, the data of them are indicated with arrows in the figure. It can be seen that the $T_{\mathrm{R} \text { min }}$ of the composites made of $\mathrm{CB}$ of larger SA shifts to higher temperatures.

On the other hand, $T_{\mathrm{R} \text { min }}$ also depends on

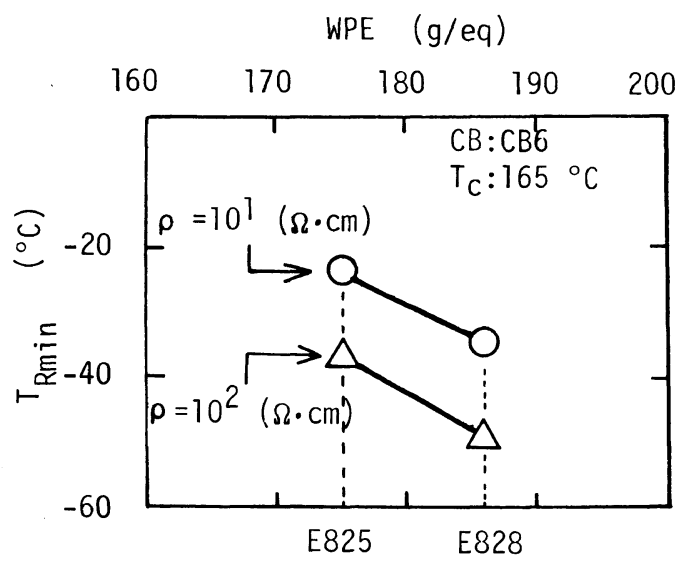

Figure 4. $T_{\mathrm{R} \min }$ as a function of weight per epoxide (WPE).

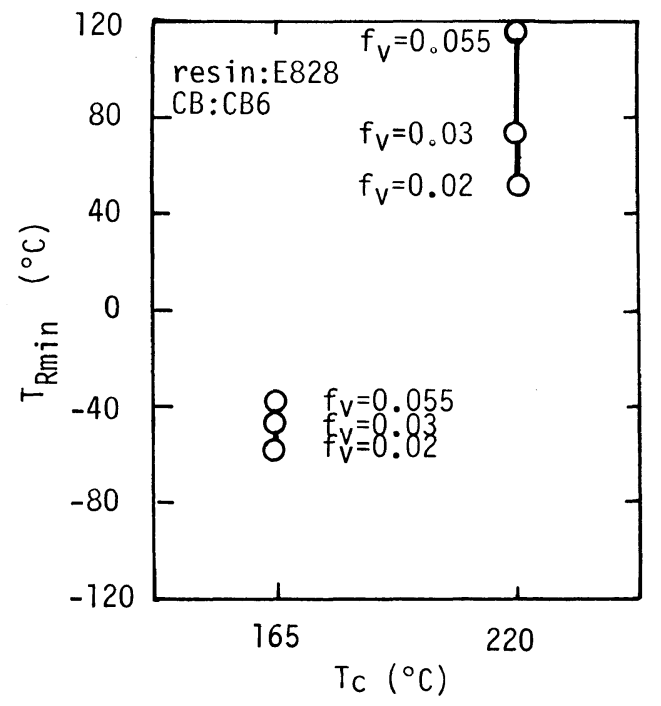

Figure 5. Dependence of $T_{\mathrm{R} \min }$ on curing temperature $T_{\mathrm{c}}$.

the weight per epoxide equivalent (WPE) of epoxy resin. Figure 4 shows the dependence of $T_{\mathrm{R} \text { min }}$ on WPE. The value of $T_{\mathrm{R} \text { min }}$ shifts to higher temperatures when the WPE becomes small. From the figure, it can be also seen that $T_{\mathrm{R} \text { min }}$ moves to higher temperatures with decreasing resistivity by loading more CB content.

As shown in Figures 3 and 4 , the $T_{\mathrm{R} \min }$ is influenced by the properties of $\mathrm{CB}$ and resins. It is also changed by curing temperature $T_{\mathrm{c}}$. Figure 5 shows the dependence of $T_{\mathrm{R} \min }$ on $T_{\mathrm{c}}$. 


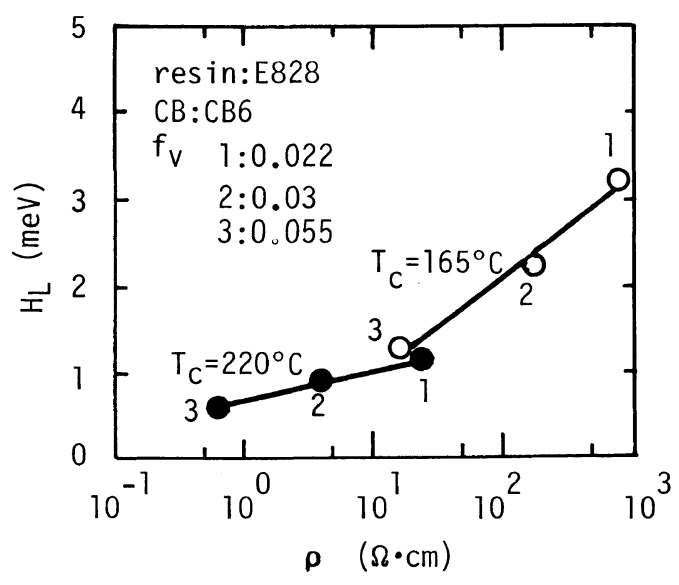

Figure 6. Dependence of the activation energy, $H_{\mathrm{L}}$, of the resistance in the low temperature region below $-20^{\circ} \mathrm{C}$ on resistivity.

The CB and resin used were CB6 and E828, respectively. The change in $T_{\mathrm{R} \min }$ by $T_{\mathrm{c}}$ is extremely large and is as much as that by varying the property CB as seen in Figure 3.

Figure 6 shows the dependence of the activation energy $H_{\mathrm{L}}$ on resistivity obtained from Arrhenius' equation in the low temperature region below $-20^{\circ} \mathrm{C}$. The volume fractions of the composites cured at $220^{\circ} \mathrm{C}$ are the same as those at $165^{\circ} \mathrm{C}$. Values of $H_{\mathrm{L}}$ for the composites cured at $T_{\mathrm{c}}=165^{\circ} \mathrm{C}$ are in the range from $1 \mathrm{meV}$ to $3 \mathrm{meV}$ and decrease with decreasing resistivity. Values of $H_{\mathrm{L}}$ were decreased by curing at high $T_{\mathrm{c}}$ of $220^{\circ} \mathrm{C}$.

\section{Experimental Results around Glass Transition Temperature}

In Figure 7, $T_{\mathrm{R}_{\max }}$ is shown as a function of $f_{\mathrm{v}}$. The glass transition temperature, $T_{\mathrm{g}}$, of E828 cured at $T_{\mathrm{c}}=165^{\circ} \mathrm{C}$ exists around $137^{\circ} \mathrm{C}$ as shown in Figure 7 . By curing at $220^{\circ} \mathrm{C}, T_{\mathrm{g}}$ shifts to lower temperature. This lowering may be due to a thermal degradation of resin caused by high $T_{\mathrm{c}}$. It is important to clarify the change of $T_{\mathrm{R} \max }$ by curing temperature. Namely, the values of $T_{\mathrm{R} \max }$ are below $T_{\mathrm{g}}$ for curing temperature of $165^{\circ} \mathrm{C}$. On the other hand, $T_{\mathrm{R} \max }$ shifts to much higher temperature than $T_{\mathrm{g}}$ by curing at $220^{\circ} \mathrm{C}$ nevertheless the $T_{\mathrm{g}}$ of

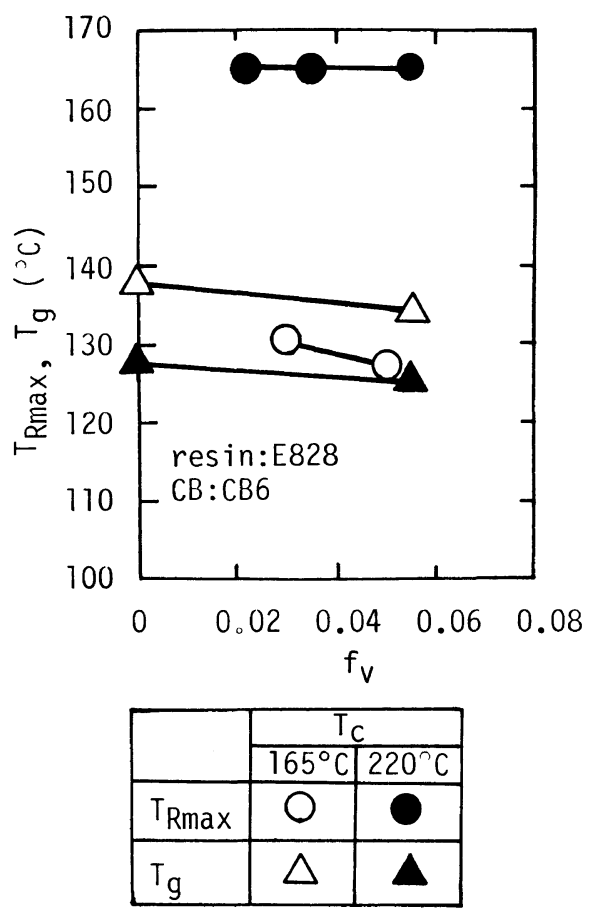

Figure 7. $T_{\mathrm{g}}$ and $T_{\mathrm{R} \max }$ as a function of the volume fraction, $f_{\mathrm{v}}$, of CB.

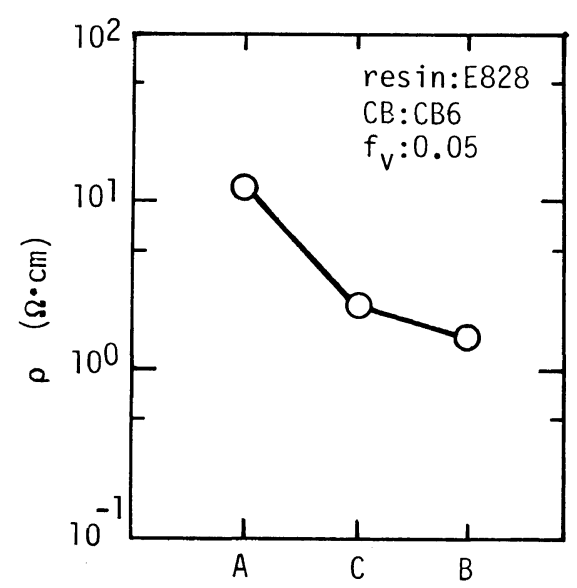

Figure 8. Change of resistivity by curing conditions. Condition A means that $T_{\mathrm{c}}=165^{\circ} \mathrm{C}, \mathrm{B}$ for $T_{\mathrm{c}}=210^{\circ} \mathrm{C}$. Condition $\mathrm{C}$ means that the conditions $\mathrm{B}$ was applied after condition A.

the resin cured at $T_{\mathrm{c}}=220^{\circ} \mathrm{C}$ shifts to a lower temperature than that at $T_{\mathrm{c}}=165^{\circ} \mathrm{C}$, which is at least by $30^{\circ} \mathrm{C}$ higher than that at $T_{\mathrm{c}}=165^{\circ} \mathrm{C}$.

Figure 8 shows the change in resistivity by 
curing conditions. The condition $\mathrm{A}$ on the abscissa indicates that $T_{\mathrm{c}}$ is $165^{\circ} \mathrm{C}$, and the condition $\mathrm{B}$ is $T_{\mathrm{c}}=210^{\circ} \mathrm{C}$. The condition $\mathrm{C}$ means that the composite was cured again at $210^{\circ} \mathrm{C}$ after it had been previously cured at $165^{\circ} \mathrm{C}$. The resistivity of about $2.5 \times 10^{1} \Omega$ $\mathrm{cm}$ for $T_{\mathrm{c}}=165^{\circ} \mathrm{C}$ (condition $\mathrm{A}$ ) is almost by a factor of 10 larger than that for $T_{\mathrm{c}}=210^{\circ} \mathrm{C}$ (condition $\mathrm{B}$ ). The resistivity for condition $\mathrm{C}$ is decreased by the further curing and is close to the resistivity for the composite cured at $210^{\circ} \mathrm{C}$ as shown in Figure 8.

\section{Humidity Dependence of Resistance}

The humidity dependence of resistance was measured by changing the relative humidity of environment. The percent change of resistance was normalized by the resistance at $40 \%$ relative humidity. Usually, the percent change of resistance shows a linear dependence on the relative humidity. ${ }^{22}$ Therefore, the value of humidity coefficient of resistance (HCR) was estimated from the slope on the relative humidity (\%)-percent change of resistance $(\%)$ curve. The value of HCR means that how much the percent resistance changes by $1 \%$ relative humidity. Figure 9 shows the HCR as a function of $f_{\mathrm{v}}$. The HCR strongly depends on $f_{\mathrm{v}}$ for $T_{\mathrm{c}}=165^{\circ} \mathrm{C}$. On the other hand, the magnitude of $\mathrm{HCR}$ for $T_{\mathrm{c}}=220^{\circ} \mathrm{C}$ and the change of HCR with $f_{\mathrm{v}}$ are smaller than that for $T_{\mathrm{c}}=165^{\circ} \mathrm{C}$.

\section{DISCUSSION}

We have studied widely the temperature dependence of the resistance of the CB-resin composite in the range from about $-160^{\circ} \mathrm{C}$ to $220^{\circ} \mathrm{C}$ in order to clarify how the cohesive property of $\mathrm{CB}$ particle changes by curing temperature, properties of $\mathrm{CB}$, and resin. As shown in Figure 2, the resistivity decreases with raising temperature below room temperature. It has been concluded that the electrical conduction in low temperatures is governed by the thermally activated mechanism. However,

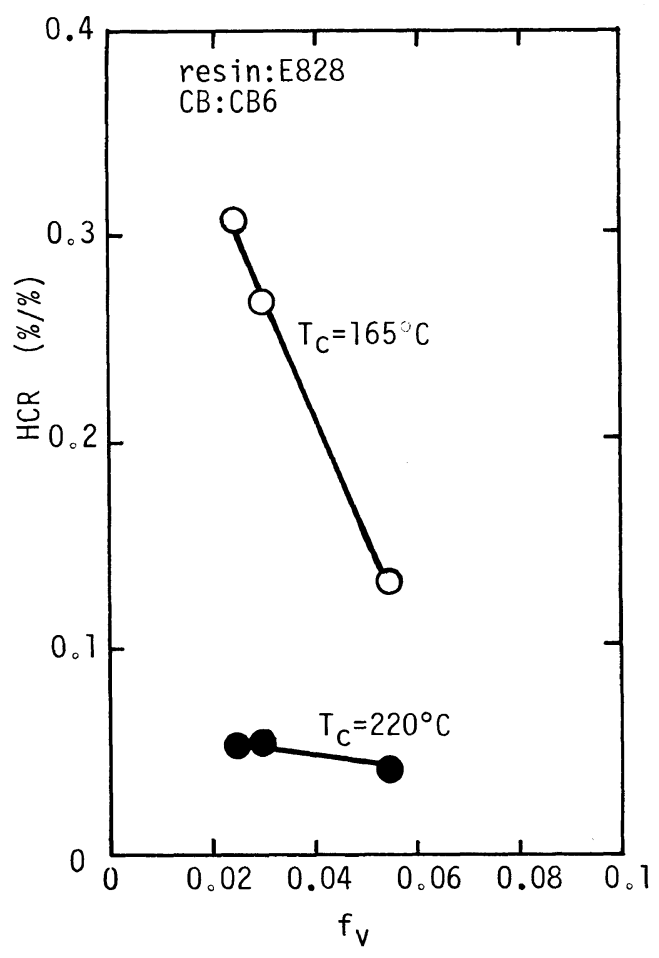

Figure 9. Dependence of HCR on carbon black content $f_{\mathrm{v}}$.

once the thermal expansion of resin begins to be effective for breaking off the conducting paths or for enlarging the gap of CB particles, the resistance increases with raising temperature. As a result, $T_{\mathrm{R} \text { min }}$, where the resistance shows a minimum, appears on the temperature dependence. Therefore, it is not unreasonable that $T_{\mathrm{R} \text { min }}$ indicates a measure of cohesive property of $\mathrm{CB}$ particles. It is well known that the high structure CB's such as CB1 and CB2 show a high conductivity even if the $f_{\mathrm{v}}$ of them is far less than that of low structure CB. ${ }^{5,6,9}$ That means that the high structure CB's tend to easily form conductive paths. From Fig. 3, the $T_{\mathrm{R} \text { min }}$ shifts to higher temperatures with a larger value of SA. It is, therefore, conclusive that a high strucuture CB shows more strong cohesion than a low structure CB. The important thing in this paper is that this cohesion is drastically enhanced by curing at 
high temperature as shown in Figure 5.

By curing for $20 \mathrm{~h}$ at above $165^{\circ} \mathrm{C}$, a thermal degradation of epoxy resin may take place by causing oxidation and chain scission as suggested from a lowering of $T_{\mathrm{g}}$. An epoxy resin cured at higher temperature shows larger water absorption, which is ascribed to the thermal degradation. ${ }^{23}$ In Figure 9, HCR was decreased by curing at high temperature. There are two reasons for the decrement of HCR by adding $\mathrm{CB}$; one of them is a decrement of resin and the other is due to forming a strong cohesive structure by adding CB. Previously, we have presented that the change of resistance with humidity is due to a swelling of resin. ${ }^{19,20,22}$ Therefore, the decrement of HCR by curing at high temperature is due to a formation of strong cohesion of CB particles against swelling of resin.

The activation energy of the resistance in low temperatures as shown in Figure 6 decreases with decreasing resistance or by curing at high temperature. It means that the required thermal energy is decreased with shortening the gap between $\mathrm{CB}$ particles by loading CB or by curing at high temperature. It should be noticed that the thermal expansion of resin makes the activation energy small when it is effective in the low temperature region. The results shown in Figure 4, that the resin of smaller WPE gives a higher $T_{\mathrm{R} \text { min }}$, seem very reasonable because the resin of smaller WPE tends to give a smaller coefficient of thermal expansion and a higher glass transition temperature. ${ }^{20,22,24}$ Miyauchi et al. have presented the same result that an apperance of PTC is prevented by proceeding a crosslinking of resin. ${ }^{25}$

By heating to above $T_{\mathrm{R} \text { min }}$, the resistivity decreases around $T_{\mathrm{R} \max }$. It can be concluded that the decrement in resistivity is caused by a re-cohesion of $\mathrm{CB}$ so as to increase a number of conducting paths or to shorten the gap of CB particles under the rubber state of resin. Micro-Brownian motion of resin may enhance the re-cohesion of $\mathrm{CB}$ particles, because the change of the resistivity is irreversible for cyclic heating up to $220^{\circ} \mathrm{C}$.

As seen from Figure 7, $T_{\mathrm{R} \max }$ moves to very high temperature by curing at high temperature though the glass transition temperature seems not to change as much as $T_{\mathrm{R} \max }$. It can be said that the shift of $T_{\mathrm{R} \max }$ on curing temperature is also another example indicating the cohesive property of CB particles.

\section{CONCLUSIONS}

Temperature dependence of CB-resin composites has been studied widely from $-160^{\circ} \mathrm{C}$ to $220^{\circ} \mathrm{C}$. There are a minimum and a maximum of resistance on the temprature dependence.

The minimum of resistance appears as a result of competitive process between the decrement of resistance by thermally activated process and the increment of resistance by enlarging of the gaps of CB particles or by breaking off the conducting paths due to thermal expansion of resin. By heating above the glass transition temperature up to $220^{\circ} \mathrm{C}$, the resistance irreversibly decreases. It is caused by a re-cohesion of CB particles under the rubber state of resin.

The $T_{\mathrm{R} \text { min }}$, where the minimum of resistance appears, is a measure of cohesion property of CB particles. It shifts to higher temperatures by using a high structure CB and by curing at high temperature because of strong cohesion. Also, it shifts to higher temperatures by using a resin of smaller WPE because of small thermal expansion coefficient. The above experimental results support the electrical conduction model for the CB-resin composite which we have proposed before. ${ }^{9,19}$

The $T_{\mathrm{R}_{\text {max }}}$, where the resistance shows a maximum, also appears as a result of a competitive process between the enlargement of the gap of CB particles or the break off of the conducting paths and the re-cohesion of CB particles. It leads to a strong dependence of $T_{\mathrm{R} \max }$ on the cohesive property CB particle.

It has been presented that the humidity 
dependence of $\mathrm{CB}$-resin resistor can be improved by changing a curing temperature.

Acknowledgments. The authors wish to thank Yuka Shell Epoxy Co., Ltd., Tokyo Zairyou Co., Ltd., Lion Co., Ltd., Asahi Carbon Co., Ltd., and Mitsubishi Petrochem. Co., Ltd. for providing epoxy resins and carbon blacks. Also, the authors are grateful to $\mathrm{Mr}$. T. Koike and Dr. K. Iida for their valuable discussions and comments.

\section{REFERENCES}

1. S. Kirkpatrick, Rev. of Mod. Phys., 45574 (1973).

2. G. E. Pike and C. H. Seager, Phys. Rev. B, 10, 1421 (1974).

3. R. P. Kusy, J. Appl. Phys., 48, 5301 (1977).

4. K. Miyasaka, K. Watanabe, E. Jojima, H. Aida, M. Sumita, and K. Ishikawa: J. Mater. Sci., 17, 1610 (1982).

5. E. K. Sichel, J. I. Gittleman, and P. Sheng, J. Electronic Mater., 11, 699 (1982).

6. M. Sumita, E. Jojima, H. Aida, K. Miyasaka, and K. Ishikawa, Kobunshi Ronbunshu, 40, 203 (1983).

7. P. Sheng, Phys. Rev. B, 21, 2180 (1980).

8. E. K. Sichel; J. I. Gittleman, and P. Sheng, Phys. Rev. B, 185712 (1978).

9. S. Nakamura, A. Ito, S. Ogasawara, H. Kato, G. Sawa, S. Orita, and K. Tsubota, Trans. Inst. Electr. Inform. Commun., J70-C (1), 103 (1987).

10. E. K. Sichel, Ed., "Carbon Black-Polymer Compo- sites," Marcel Dekker, Inc., New York and Basel, 1982, Chapter 2.

11. A. Kusy, J. Appl. Phys., 62, 1324 (1987).

12. Morisaki and K. Yazawa, Japan Academic Promotion Association, No. 131 Committee, No. 73 Meeting, 9 (1975).

13. R. D. Sherman, L. M. Middleman, and S. M. Jacobs, Polym. Eng. Sci., 23, 36 (1983).

14. M. Narkis, A. Ram, and F. Flashner, Polym. Eng. Sci., 18, 649 (1978).

15. M. Narkis, A. Ram, and F. Flashner, J. Appl. Polym. Sci., 22, 1163 (1978).

16. F. Bueche, J. Polym. Sci., Polym. Phys. Ed., 11, 1319 (1973).

17. W. Martin, Circuit Manufacturing, May, 74 (1977).

18. R. M. Scarisbrick, J. Phys. D, 6, 2098 (1973).

19. S. Nakamura, A. Ito, G. Sawa, K. Tsubota, M. Ikeda, and T. Kubo, Trans. Inst. Electr. Inform. Commun., J72-CII (8), 795 (1989).

20. S. Nakamura, A. Ito, G. Sawa, K. Tsubota, M. Ikeda, and T. Kubo, Trans. Inst. Electr. Inform. Commun., J72-CII (12), 1046 (1989).

21. Carbon Black Association ed, "Hand Book of Carbon Black," Tosho Shuppan Co., Ltd., Tokyo, 1973, Chapter IV.

22. S. Nakamura, A. Ito, G. Sawa, K. Tsubota, M. Ikeda, and T. Kubo, IEICE Tech. Rept., CPM89-62 (1989-10-27).

23. S. Nakamura, A. Ito, G. Sawa, K. Tsubota, M. Ikeda, and T. Kubo, in preparing the manuscript.

24. S. C. Misra, J. A. Manson, and L. H. Sperling, Am. Chem. Soc., Symp. Ser., 114, 137 (1979).

25. S. Miyauchi, E. Togashi, Y. Sorimachi, and J. Tsubota, Kobunshi Ronbunshu, 40, 195 (1983). 